\title{
High Prevalence of Fecal Carriage of Extended Spectrum $\beta$-Lactamase-Producing Enterobacteriaceae Among Newly HIV-Diagnosed Adults in a Community Setting in Tanzania
}

\author{
Joel Manyahi, ${ }^{1-3}$ Sabrina John Moyo, ${ }^{1,3}$ Marit Gjerde Tellevik, ${ }^{2}$ Nina Langeland, ${ }^{1,2}$ and Bjørn Blomberg ${ }^{1,2}$
}

Colonization in HIV-infected populations with extended-spectrum $\beta$-lactamase-producing Enterobacteriaceae (ESBL-PE) is particularly worrisome in low-income settings. This study describes the prevalence of ESBL-PE carriage and associated risk factors among newly HIV-diagnosed adults in a community setting in Tanzania. A total of 595 newly diagnosed HIV-positive adults with a median age of 35 years with interquartile range (IQR) 29-42 years and a median CD4 count of 492 cells/ $\mu \mathrm{L}$ (IQR 390-666 cells/ $\mu \mathrm{L}$ ) were recruited. Among these, 194/595 (32.6\%, 95\% confidence interval [CI] 28.9-36.6) were ESBL-PE carriers. Participants with low CD4 count $(<350$ cells $/ \mu \mathrm{L})$ had significantly higher prevalence of ESBL-PE carriage compared with those with CD4 count $\geq 350$ cells $/ \mu \mathrm{L}(26 / 58,44.8 \%$, vs. $168 / 537,31.3 \%, p=0.04)$. Antibiotic use in last 4 weeks (odds ratio [OR] 1.55, 95\% CI 1.08-2.22, $p=0.02$ ) and CD4 count $<350$ cells $/ \mu \mathrm{L}$ (OR 1.78, 95\% CI 1.03-3.09, $p=0.04$ ) were independent risk factors for fecal carriage of ESBL-PE. In total, 244 isolates of ESBL-PE were isolated from 194 participants. Of these, 238/244 (97.5\%) harbored bla $a_{\text {CTX-M }}$ genes, with bla $a_{\text {CTX-M-15 }}$ being predominant $\left(219 / 238(92 \%)\right.$, followed by bla $a_{\text {CTX-M-27 }}\left(9 / 238\right.$ (3.8\%), bla CTX-M-14 $\left(8 / 238(3.4 \%)\right.$, bla $_{\text {CTX-M-55 }}$ (1/238), and $b l a_{\mathrm{CTX}-\mathrm{M} 211 / 3}(1 / 238)$. bla $a_{\mathrm{SHV}-2 \mathrm{a}}$ genes were detected in four isolates, whereas the bla $a_{\mathrm{SHV}-12}$ gene was detected in one isolate. Phenotypic carbapenemase-producing Enterobacteriaceae was detected in one HIVpositive person with CD4 count 132 cells $/ \mu \mathrm{L}$. In conclusion prevalence of ESBL-PE carriage is high among newly diagnosed HIV adults in Dar es Salaam, and is significantly associated antibiotic use and low CD4 count.

Keywords: ESBL, HIV, community, Tanzania

\section{Introduction}

I NDIVIDUALS LIVING WITH HIV are at risk not only of classical HIV-related opportunistic infections such as pneumocystis pneumonia and tuberculosis, but also severe infections caused by common bacterial pathogens such as Escherichia coli, salmonella, pneumococci, and staphylococci. $^{1-3}$ The World Health Organization (WHO) recognizes antimicrobial resistance (AMR) in such bacterial infections as a major threat to global health. Extended-spectrum $\beta$ lactamase-producing Enterobacteriaceae (ESBL-PE) constitute a particular challenge, as almost all are multidrug resistant. Previously, infections due to ESBL producers were mainly a health care-associated problem. ${ }^{4,5}$ However, ESBL-PE infections are now increasingly acquired in the community. ${ }^{6,7}$

In resource-constrained settings, ESBL-PE infections are spread more easily due to deficient infection control, whereas expensive reserve antibiotics such as carbapenems and colistin are inaccessible. Consequently, infections caused by ESBL-PE carries high mortality exceeding mortality outcome of bacterial infections in the preantibiotic era. ${ }^{5,8}$

Colonization with ESBL-PE frequently precedes invasive diseases. ${ }^{9,10}$ Fecal carriage of ESBL-PE could pose greater risk in people living with HIV due to the increased risk of severe bacterial infections. ${ }^{1,2}$ In Tanzania, studies have documented high frequency of infections caused by ESBL-PE

\footnotetext{
${ }^{1}$ Department of Clinical Science, University of Bergen, Bergen, Norway.

${ }^{2}$ National Advisory Unit on Tropical Infectious Diseases, Haukeland University Hospital, Bergen, Norway.

${ }^{3}$ Department of Microbiology and Immunology, Muhimbili University of Health and Allied Sciences, Dar es Salaam, Tanzania.

(C) Joel Manyahi et al., 2020; Published by Mary Ann Liebert, Inc. This Open Access article is distributed under the terms of the Creative Commons License (http://creativecommons.org/licenses/by/4.0), which permits unrestricted use, distribution, and reproduction in any medium, provided the original work is properly cited.
} 
in hospitalized patients. ${ }^{5,11-13}$ ESBL-PE carriage is also common in hospital settings, and carriage rates of 50\% have been documented in hospitalized children in Tanzania. ${ }^{14}$ Even in community settings, studies have documented ESBLPE carriage rates of $11-32 \%$ in healthy children ${ }^{15}$ and $17 \%$ in healthy adults ${ }^{16}$ in the same country. Although high rates (89.7\%) of ESBL-PE carriage have been reported in hospitalized HIV positive children in Tanzania, ${ }^{14}$ others documented lower rates $(14 \%)$ in HIV-infected children in the community in Zimbabwe. ${ }^{17}$ To date, no community-based studies from Africa have reported frequencies and risk factors for ESBL-PE carriage among newly diagnosed HIV adults.

$\mathrm{HIV}$ is pandemic in sub-Saharan Africa, and Tanzania has an estimated 1.4 million people aged between 15 and 64 years living with HIV. ${ }^{18}$ We designed this study aimed to determine prevalence of fecal carriage of ESBL producers in HIV-infected people in the community; and assess any influence of antibiotic use, hospitalization, and CD4 count on fecal carriage of ESBL producers. The findings may help develop strategies for reducing the burden of AMR in a population at high risk of severe infections.

\section{Materials and Methods}

\section{Study sites and study participants}

Newly diagnosed HIV-infected adults with CD4 count of $\geq 350$ cells $/ \mu \mathrm{L}$ who had not yet started antiretroviral treatment (ART) were recruited consecutively as part of a double-blinded randomized clinical trial (RCT), CoTrimResist (ClinicalTrials.gov identifier: NCT03087890) between April 2017 and May 2018. The study was performed in Dar es Salaam, Tanzania, the largest city and economic capital of Tanzania. Participants were residents of the main municipals of Dar es Salaam city, namely Kinondoni, Temeke, Ilala, Ubungo, and Kigamboni, and were recruited through six HIV care and treatment clinics at Mwananyamala Hospital, Amana Hospital, Temeke Hospital, Pastoral Activities and Services for People with AIDS Dar es Salaam Archdiocese (PASADA), Mbagala Hospital, and Mnazimmoja Hospital. In addition, newly diagnosed HIV-infected adults with CD4 counts of $<350$ cells $/ \mu \mathrm{L}(n=58)$ were recruited from the same Hospitals during screening for eligibility to the RCT. This article reports on the baseline data before interventions and treatment.

\section{Data collection}

Health workers recorded participants' data such as demographics and clinical parameters on tablet computers using standardized electronic case report forms employing the RedCAP system (Research Electronic Data Capture, Vanderbilt University, Nashville, TN), which automatically synchronizes study data to a central data server.

\section{Screening for ESBL-}

\section{and carbapenemase-producing Enterobacteriaceae}

From each participant, a rectal swab was collected and transported in liquid Cary-Blair medium (Fecal Transwab, MWE Co Bath Ltd., Corsham, United Kingdom) in a cool box and maintained at $4^{\circ} \mathrm{C}$ with icepack. Rectal swabs were inoculated into brain heart infusion (BHI) broth and incubated overnight at $37^{\circ} \mathrm{C}$. Two drops $(0.1 \mathrm{~mL})$ from $\mathrm{BHI}$ broth were subcultured on CHROMID ESBL (BioMérieux,
Marcy l'Etoile, France) for screening of ESBL-PE, ${ }^{19}$ and CHROMID CARBA SMART (BioMérieux) for combined screening for carbapenemase-producing Enterobacteriaceae (CPE) and OXA-48-producing Enterobacteriaceae. The plates were incubated at $37^{\circ} \mathrm{C}$ for 24 hours and bacterial growth interpreted according to manufacturer's instructions. Molecular characterized strains harboring different combinations of $\beta$-lactamases were used for quality control as previously described. ${ }^{14}$

Bacterial isolates were identified by MALDI-TOF MS using the Microflex LT instrument and MALDI Biotyper 3.1 software (Bruker Daltonics, Bremen, Germany).

\section{$P C R$ and sequencing for detection and identification of ESBL genes}

DNA was extracted by a rapid boiling procedure and stored at $-20^{\circ} \mathrm{C}$. Real-time PCR was used for detection of cefotaximeMunich (CTX-M) encoding genes using a LightCycler 480 Instrument II (Roche Diagnostics, Mannheim, Germany). Forward primer CTXM-F 5'-ATGTGCAGYACCAGTAAR GT-3', and reverse primers CTXM-R1 5'-TGGGTGAAGTAA GTGACCAGA-3' and CTXM-R2 5'-TGGGTAAARTAGG TCACCAGA-3' (TIB Molbiol, Berlin, Germany), which target a 595 bp internal region present in all the five different CTX-M groups, were used as previously described. ${ }^{14}$ Each run included positive and negative controls in duplicates. The PCR products were sequenced using the same reverse primers as for PCR. Sequencing was done using BigDye Terminator v1.1 Cycle Sequencing Kit (Applied Biosystems, Foster City, CA). Sequences were analyzed using the Basic Local Alignment Search Tool program available at the website of the National Center for Biotechnology Information.

For confirmation of ESBL producers, isolates negative for CTX-M PCR were tested for the presence of $b l a_{\text {SHV }}$ genes as previously described by Kommedal et al. ${ }^{20}$

\section{Statistical analysis}

We used chi-square test to assess the proportions of fecal carriage of ESBL producers by patient characteristics. We analyzed the association between risk factors of interest (antibiotic use, prior hospitalization, and low CD4 counts) and fecal carriage of ESBL producers, adjusting for age, gender, education status, district of residence, and study sites (individual study sites). For each main exposure variable, we assessed all potential confounders using both logistic regression and Mantel-Haenszel method, defining a confounder as a factor that changes the effect size by $\geq 10 \%$. Effect modification of factor between different groups were examined by Mantel-Haenszel method. A significance level of 0.05 was used and all $p$-values refer to two-sided tests. Statistical analysis was performed using STATA version 16 (College Station, TX).

\section{Ethical approval and consent to participate}

Ethical approval to conduct the study in Tanzania was obtained from Muhimbili University of Heath and Allied Sciences senate research and publication committee (Ref. No. 2015-10-27/Vol.X/54)—Muhimbili University of Health and Allied Sciences, National Institute for Medical Research (NIMR/HQ/R.8a/Vol.IX/2144)_-Tanzania, Ministry of Health, 
Community development, Gender, Elderly, and Children. The clinical trial was also registered by Tanzania Food and Drugs Authority (TZ16CT007) and Clinical trial.org (NCT03087890). In Norway, the study was approved by the Regional Committee for Medical and Health Research Ethics of Western Norway (REK2015/540). Informed written consent was obtained from each of the study participants.

\section{Results}

\section{Description of study participants}

We recruited a total of 595 newly HIV-diagnosed adults with a median age of 35 years with interquartile range (IQR) 29-42 years and a median CD4 count of 492 cells/ $\mu \mathrm{L}$ with IQR 390-666 cells $\mu \mathrm{L}$. Among these, 537 (90.2\%) were newly diagnosed HIV seropositive individuals with CD4 counts $\geq 350$ cells $/ \mu \mathrm{L}$ (median 518 IQR 413-687) and 58 (9.8\%) were newly diagnosed HIV seropositive individuals with CD4 counts of $<350$ cells $/ \mu \mathrm{L}$ (median 159 IQR $61-$ 259). Out of 595, 451 (75.8\%) were female and 233 (39.2\%) were aged between 30 and 39 years. The majority, 360/595 $(60.5 \%)$, of the HIV seropositive individuals had WHO stage 1 HIV disease. Although 64/595 (10.8\%) of participants had been admitted to hospital within the last year, 191/ $595(31.7 \%)$ reported use of antibiotics during the last 4 weeks before enrollment (Table 1).

\section{Prevalence of ESBL carriage and identification of the bacterial isolates}

The overall prevalence of fecal carriage of ESBL-PE was 194/595 (32.6\%, 95\% confidence interval [CI] 28.9-36.6), and the proportions of carriage in subgroups are shown in Table 2. The prevalence of fecal carriage of ESBL-PE varied between study sites (Table 2). Participants with low CD4 counts $(<350$ cells $/ \mu \mathrm{L})$ had significantly higher prevalence of ESBL-PE carriage than those with higher CD4 counts $(44.8 \%, 26 / 58$ vs. $31.3 \%, 168 / 537, p=0.04)$.

A total of 244 isolates of Enterobacteriaceae were isolated from 194 participants harboring ESBL-PE phenotypes. The majority of participants, $74.2 \%$, were colonized by a single ESBL-PE isolate, whereas 50/194 (25.8\%) had two or more bacterial isolates. E. coli was the predominant microbe, 209/244 (85.7\%), followed by Klebsiella pneumoniae, 33/244 (13.5\%), and Enterobacter cloacae, 2/244 $(0.8 \%)$. Patients with CD4 counts $<350$ cells $/ \mu \mathrm{L}$ were more likely to carry multiple isolates of ESBL-PE than those with higher CD4 counts $(15.5 \%, 9 / 58$ vs. $6.9 \%, 37 / 537, p=0.02)$. One E. coli isolate was $\mathrm{CPE}$ and isolated from an HIV participant with CD4 count 132 cells/ $\mu \mathrm{L}$.

\section{ESBL genotypes}

PCR confirmed ESBL genotype for 242/244 (99.2\%) of isolates with phenotypic ESBL-PE. The majority, 238 (97.5\%), harbored bla $_{\mathrm{CTX}-\mathrm{M}}$ encoding genes. The most predominant bla $_{\text {СТХ-M }}$ gene was bla $_{\text {CTX-M-15 }}(219 / 238,92 \%)$, followed

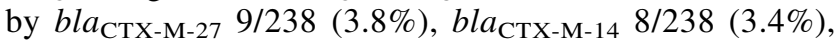
bla $a_{\mathrm{CTX}-\mathrm{M}-55}$ (1/238), and bla $a_{\mathrm{CTX}-\mathrm{M}} 211 / 3$ (1/238). All $K$. pneumoniae and E. cloacae isolates carried the bla $a_{\mathrm{CTX}-\mathrm{M}-15}$ gene only, whereas $E$. coli displayed a diversity of $b l a_{\mathrm{CTX}-\mathrm{M}}$
Table 1. (Clinical Demographics) Characteristics of THE Study Participants

\begin{tabular}{|c|c|c|}
\hline Variable & Frequency & Percentage \\
\hline \multicolumn{3}{|l|}{ Gender } \\
\hline Female & 451 & 75.8 \\
\hline Male & 144 & 24.2 \\
\hline \multicolumn{3}{|l|}{ Age (years) } \\
\hline Up to 29 & 165 & 27.7 \\
\hline $30-39$ & 233 & 39.2 \\
\hline $40-49$ & 148 & 24.9 \\
\hline $50-59$ & 33 & 5.5 \\
\hline 60 and above & 16 & 2.7 \\
\hline \multicolumn{3}{|l|}{ Education } \\
\hline Primary school & 388 & 65.2 \\
\hline Secondary & 126 & 21.2 \\
\hline Postsecondary & 24 & 4.0 \\
\hline None/informal & 57 & 9.6 \\
\hline \multicolumn{3}{|l|}{ District of residence } \\
\hline Temeke & 289 & 48.6 \\
\hline Kinondoni & 114 & 19.1 \\
\hline Ubungo & 32 & 5.4 \\
\hline Ilala & 139 & 23.4 \\
\hline Kigamboni & 12 & 2.0 \\
\hline Others & 9 & 1.5 \\
\hline \multicolumn{3}{|l|}{ HIV stage } \\
\hline 1 & 360 & 60.5 \\
\hline 2 & 173 & 29.1 \\
\hline 3 & 59 & 9.9 \\
\hline 4 & 3 & 0.5 \\
\hline \multicolumn{3}{|c|}{ CD4 counts (cells $/ \mu \mathrm{L})$} \\
\hline$\geq 350$ & 537 & 90.2 \\
\hline$<350$ & 58 & 9.8 \\
\hline \multicolumn{3}{|l|}{ Study site } \\
\hline PASADA & 168 & 28.2 \\
\hline Temeke & 54 & 9.1 \\
\hline Amana & 30 & 5.0 \\
\hline Mwananyamala & 100 & 16.8 \\
\hline Mbagala & 124 & 20.9 \\
\hline Mnazimmoja & 119 & 20.0 \\
\hline \multicolumn{3}{|c|}{ Hospital admission within last year } \\
\hline No & 531 & 89.2 \\
\hline Yes & 64 & 10.8 \\
\hline \multicolumn{3}{|c|}{ Antibiotic use last 4 weeks } \\
\hline No & 404 & 67.9 \\
\hline Yes & 191 & 32.1 \\
\hline
\end{tabular}

PASADA, Pastoral Activities and Services for People with AIDS Dar es Salaam Archdiocese.

genes, including the ones mentioned earlier. $B l a_{\mathrm{SHV}-2 \mathrm{a}}$ genes were detected in two E. coli and two K. pneumonia, whereas the $b l a_{\mathrm{SHV}-12}$ gene was detected in one E. coli.

\section{Predictors of ESBL producers}

Among the main risk factors of interest, only antibiotic use during the last 4 weeks (odds ratio [OR] $1.55,95 \% \mathrm{CI}$ $1.08-2.22, p=0.02$ ) and CD4 count $<350$ cells $/ \mu \mathrm{L}$ (OR 1.78, $95 \%$ CI 1.03-3.09, $p=0.04$ ) were independently associated with fecal carriage of ESBL producers (Table 3). Prior hospitalization during the last 1 year was not a significant risk factor (OR $0.79,95 \%$ CI $0.44-1.40, p=0.41$ ). The effect size of each risk factors did not change significantly 
Table 2. Prevalence of Extended-Spectrum

$\beta$-Lactamase-Producing BaCteria

by Clinical-Demographic Characteristics

\begin{tabular}{|c|c|c|c|}
\hline Variable & Frequency & $\begin{array}{c}\text { Prevalence } \\
\text { of ESBL, } \\
\%(\mathrm{n})\end{array}$ & $\begin{array}{c}\text { Prevalence } \\
\text { of ESBL, } \\
\%(\mathrm{n})\end{array}$ \\
\hline \multicolumn{4}{|l|}{ Gender } \\
\hline Female & 451 & $32.6(147)$ & \\
\hline Male & 144 & $32.6(47)$ & 1.000 \\
\hline \multicolumn{4}{|l|}{ Age (years) } \\
\hline Up to 29 & 165 & $35.8(59)$ & \\
\hline $30-39$ & 233 & $30.0(70)$ & \\
\hline $40-49$ & 148 & $32.8(50)$ & \\
\hline $50-59$ & 33 & $18.2(6)$ & \\
\hline 60 and above & 16 & $56.3(9)$ & 0.068 \\
\hline \multicolumn{4}{|l|}{ Education } \\
\hline Primary school & 388 & 30.2 (117) & \\
\hline Secondary & 126 & $31.7(40)$ & \\
\hline Postsecondary & 24 & $50.0(12)$ & \\
\hline None/informal & 57 & $43.9(25)$ & 0.053 \\
\hline \multicolumn{4}{|l|}{ District of residence } \\
\hline Temeke & 289 & $29.4(85)$ & \\
\hline Kinondoni & 114 & $38.6(44)$ & \\
\hline Ubungo & 32 & $34.4(11)$ & \\
\hline Ilala & 139 & $36.7(51)$ & \\
\hline Kigamboni & 12 & $0.0(0)$ & \\
\hline Others & 9 & $33.3(3)$ & 0.072 \\
\hline \multicolumn{4}{|l|}{ HIV stage } \\
\hline 1 & 360 & $31.9(115)$ & \\
\hline 2 & 173 & $31.8(55)$ & \\
\hline 3 & 59 & $40.7(24)$ & \\
\hline 4 & 3 & $0.0(0)$ & 0.344 \\
\hline \multicolumn{4}{|c|}{ CD4 counts (cells $/ \mu \mathrm{L})$} \\
\hline$\geq 350$ & 537 & $31.3(168)$ & \\
\hline$<350$ & 58 & $44.8(26)$ & $0.037 *$ \\
\hline \multicolumn{4}{|l|}{ Study site } \\
\hline PASADA & 168 & $22.0(37)$ & \\
\hline Temeke & 54 & $20.4(11)$ & \\
\hline Amana & 30 & $33.3(10)$ & \\
\hline Mwananyamala & 100 & $40.0(40)$ & \\
\hline Mbagala & 124 & $39.5(49)$ & \\
\hline Mnazimmoja & 119 & $39.5(47)$ & $0.001 *$ \\
\hline \multicolumn{4}{|c|}{ Hospital admission within last year } \\
\hline No & 531 & $33.1(176)$ & \\
\hline Yes & 64 & $28.1(18)$ & 0.418 \\
\hline \multicolumn{4}{|c|}{ Antibiotic use last 4 weeks } \\
\hline No & 404 & 29.5 (119) & \\
\hline Yes & 191 & $39.3(75)$ & $0.017 *$ \\
\hline
\end{tabular}

*p-Values calculated by chi-square test with 0.05 as cutoff for statistical significance.

ESBL, extended-spectrum $\beta$-lactamase.

(>10\%), whereas adjusting for the other main risk factors and potential confounders and effect modifiers, that is, age, gender, education status, district of residence, and study sites (individual study site). Thus, we did not find any significant confounders or effect modifiers.

\section{Discussion}

This first community-based study reports prevalence of fecal carriage of ESBL-PE in almost one third (194/595,
Table 3. Risk Factors for Fecal Carriage of EXTENDED-SPECTRUM $\beta$-LACTAMASE Producers in HIV Patients

\begin{tabular}{|c|c|c|c|c|c|}
\hline Variable & Frequency & $\begin{array}{c}\text { ESBL } \\
\text { carriage, } \\
\%(\mathrm{n})\end{array}$ & $O R$ & $95 \% C I$ & $\mathrm{p}$ \\
\hline \multicolumn{6}{|c|}{ CD 4 counts $($ cells $/ \mu \mathrm{L}) *$} \\
\hline$\geq 350$ & 537 & $31.3(168)$ & 1 & & \\
\hline$<350$ & 58 & $44.8(26)$ & 1.78 & $1.03-3.09$ & 0.04 \\
\hline \multicolumn{6}{|c|}{ Antibiotic use last 4 weeks ${ }^{\dagger}$} \\
\hline No & 404 & 29.5 (119) & & & \\
\hline Yes & 191 & $39.3(75)$ & 1.55 & $1.08-2.22$ & 0.02 \\
\hline \multicolumn{6}{|c|}{ Hospital admission within last year } \\
\hline No & 531 & $33.1(176)$ & 1 & & \\
\hline Yes & 64 & $28.1(18)$ & 0.79 & $0.44-1.40$ & 0.41 \\
\hline
\end{tabular}

*Adjusted for antibiotic use in last 4 weeks, study sites, hospital admission with last year, age, gender, and education status.

${ }^{\dagger}$ Adjusting for age, gender, education status, hospital admission within last year, CD4 count and study sites.

CI, confidence interval; OR, odds ratio.

$32.6 \%$ ) of individuals newly diagnosed with HIV in Dar es Salaam. This rate of ESBL-PE fecal carriage is much higher than found among adults with unknown HIV status in community-based studies in Northern Tanzania (55/334, $16.5 \%, p<0.001),{ }^{16}$ Burkina Faso $(22 / 101,21.8 \%, p=0.03),{ }^{21}$ Gambia (28/565, 5.0\%, $p<0.001){ }^{22}$ and Morocco (4/93, 4.3\%, $p<0.001) .^{23}$ Although we are not aware of other communitybased studies from HIV-infected adults in Africa, there was significantly lower ESBL-PE carriage rate (24/175 13.7\%, $p<0.001)$ in a community-based studies of HIV-infected children in Zimbabwe. ${ }^{17}$ The high carriage rate observed in our study could be attributed to several factors, including the choice of screening technique employed. Our use of broth enrichment of rectal swabs may have increased the yield in detecting ESBL-PE colonization. ${ }^{24,25}$ In contrast, our use of rectal swabs may have inferior sensitivity compared with stool culture used in other studies. ${ }^{19}$

We observed that antibiotic use during the last 4 weeks was a strong risk factor for fecal carriage of ESBL producers in this cohort. In Tanzania, almost all antibiotics can be accessed over the counter. Overuse of antibiotics and misuse of broadspectrum antibiotics, such as cephalosporins for trivial infections, are known to contribute to increasing AMR, including ESBL-PE. In this setting, people with an undiagnosed HIV infection are likely to opt for self-medication with antibiotics for intercurrent infections and symptoms related to an, as yet, unrecognized immunodeficiency. Such overuse of antibiotics may partially explain the high prevalence of ESBL-PE carriage in our study. This study confirms our hypothesis that antibiotic use affects carriage of resistant bacteria in HIV populations, and our finding is consistent with earlier observations from community and hospital settings in Africa. ${ }^{14,16,21,22}$

Previous hospitalization is a well-known risk factor for fecal carriage of ESBL producers, ${ }^{12,21}$ contributing both to increased likelihood of antibiotics uses and acquisition of ESBL producers in gastrointestinal tract. However, this study could not add support this observation. Tanzania's current implementation of the "test and treat" strategy for HIV is expected to result in more people getting diagnosed before actually experiencing symptomatic disease. Despite this, it is 
plausible that many patients will have consulted health care services, without actually having been admitted, for unknown HIV-related ailments before getting diagnosed with HIV, and that this may have led to increased risks of gastrointestinal colonization with ESBL-PE.

This study found low CD4 count $(<350$ cells/ $\mu \mathrm{L})$ was an independent risk factor for fecal carriage of ESBL. Low immunity predisposes to risk of opportunistic infections increasing the likelihood of antimicrobial use and hospitalization. However, adjustment for both antibiotic use and hospitalization did not alter the independent association between low CD count and fecal carriage of ESBL producers. Furthermore, Wilmore et al. ${ }^{17}$ found no association between low CD count and fecal carriage of ESBL producers in children in Zimbabwe. ${ }^{17}$ The differences could be explained by inclusion criteria, this study recruited newly diagnosed HIV-infected adults not yet on ART, whereas Wilmore et al. enrolled children who were stable on ART. ${ }^{17}$

Our study confirmed $b l a_{\mathrm{CTX}-\mathrm{M}} 15$ as the predominant ESBL gene type accounting $92 \%$ of all isolates, supporting other reports on the extraordinary dissemination of the bla $a_{\mathrm{CTX}-\mathrm{M}-15}$ genotype worldwide. In the first ever report of ESBL-PE from Tanzania, ${ }^{5,13}$ we showed that bla $_{\text {CTX-M-15, }}$, alongside TEM-63, was the dominant cause of ESBL-PE bloodstream infections in Tanzania as early as 2001-2002. Later on, we found predominance of $b l a_{\mathrm{CTX}-\mathrm{M}-15}$ in clinical isolates from community-acquired urinary tract infections from 2004 (Ref. $^{7}$ ). Reports from elsewhere ${ }^{26,27}$ indicate that when $b l a_{\mathrm{CTX}-\mathrm{M}-15}$ genotype penetrates in a new landscape where other ESBL genes persist, $b l a_{\mathrm{CTX}-\mathrm{M}-15}$ tend to displace other genes and becomes predominant. All recent studies from community and hospital settings in Tanzania have supported the predominance of $b l a_{\text {CTX-M } 15}$ genes among Enterobacteriaceae isolated from feces. ${ }^{12,15,16}$ The CTX-M group 9, bla $a_{\mathrm{CTX}-\mathrm{M}-27}$, and $b l a_{\mathrm{CTX}-14}$ were also documented in this study and were only isolated from $E$. coli. This correlates with a recent study among HIV-infected children in Zimbabwe. ${ }^{17}$ Our previous study on uropathogenic isolates did not detect any bla $a_{\mathrm{CTX}-\mathrm{M}}$ group 9 genes, ${ }^{7}$ whereas a pediatric study reported only two E. coli isolates carrying bla $a_{\mathrm{CTX}-\mathrm{M}-14}$ genes and none with bla $_{\mathrm{CTX} \text {-M-27. }}{ }^{14}$ In conclusion, the study found a high prevalence of fecal ESBL-PE carriage among people newly diagnosed with HIV. Antibiotic use during the last 4 weeks and low CD4 count were risk factors for fecal carriage of ESBL producers. Further studies should investigate transmission dynamics of ESBL-PE in the community, complex factors driving the emergence of multidrug-resistant bacteria, and the relationship between ESBL-PE carriage and invasive disease. Social behavior and policies on AMR need to be crafted and regulation on antimicrobial use must be enforced.

\section{Acknowledgments}

We thank the Helse Bergen HF, Haukeland University Hospital, Norway, through project number 912132, which funded the study (funders had no role in study design, data collection and analysis, decision to publish, or preparation of the article). We also thank members of the Department of Clinical Science, University of Bergen, Norway, for their technical support during the molecular study.

\section{Disclosure Statement}

All authors disclose no commercial associations that may create a conflict of interest in connection with the study.

\section{Funding Information}

The study was funded by Western Norway Regional Health Authority (Helse Vest Regionalt Helseforetak) through PhD grant no. 912132 and project grant no 911971 , and by the National Advisory Unit for Tropical Infectious Diseases, Haukeland University Hospital, Bergen, Norway.

\section{References}

1. Hirschtick, R.E., J. Glassroth, M.C. Jordan, T.C. Wilcosky, J.M. Wallace, P.A. Kvale, N. Markowitz, M.J. Rosen, B.T. Mangura, and P.C. Hopewell. 1995. Bacterial pneumonia in persons infected with the human immunodeficiency virus. Pulmonary Complications of HIV Infection Study Group. N. Engl. J. Med. 333:845-851.

2. Madhi, S.A., A. Madhi, K. Petersen, M. Khoosal, and K.P. Klugman. 2001. Impact of human immunodeficiency virus type 1 infection on the epidemiology and outcome of bacterial Meningitis in South African children. Int. J. Infect. Dis. 5:119-125.

3. O'Connor, J., M.J. Vjecha, A.N. Phillips, B. Angus, D. Cooper, B. Grinsztejn, G. Lopardo, S. Das, R. Wood, A. Wilkin, H. Klinker, P. Kantipong, K.L. Klingman, D. Jilich, E. Herieka, E. Denning, I. Abubakar, F. Gordin, J.D. Lundgren, and INSIGHT START study group. 2017. Effect of immediate initiation of antiretroviral therapy on risk of severe bacterial infections in HIV-positive people with CD4 cell counts of more than 500 cells per muL: secondary outcome results from a randomised controlled trial. Lancet HIV. 4:e105-e112.

4. Moyo, S.J., S. Aboud, M. Kasubi, E.F. Lyamuya, and S.Y. Maselle. 2010. Antimicrobial resistance among producers and non-producers of extended spectrum beta-lactamases in urinary isolates at a tertiary Hospital in Tanzania. BMC Res. Notes. 3:348.

5. Blomberg, B., R. Jureen, K.P. Manji, B.S. Tamim, D.S. Mwakagile, W.K. Urassa, M. Fataki, V. Msangi, M.G. Tellevik, S.Y. Maselle, and N. Langeland. 2005. High rate of fatal cases of pediatric septicemia caused by gram-negative bacteria with extended-spectrum beta-lactamases in Dar es Salaam, Tanzania. J. Clin. Microbiol. 43:745-749.

6. Blanco, V.M., J.J. Maya, A. Correa, M. Perenguez, J.S. Munoz, G. Motoa, C.J. Pallares, F. Rosso, L. Matta, Y. Celis, M. Garzon, and M.V. Villegas. 2016. [Prevalence and risk factors for extended-spectrum beta-lactamase-producing $E s$ cherichia coli causing community-onset urinary tract infections in Colombia]. Enferm. Infecc. Microbiol. Clin. 34:559-565.

7. Manyahi, J., S.J. Moyo, M.G. Tellevik, F. Ndugulile, W. Urassa, B. Blomberg, and N. Langeland. 2017. Detection of CTX-M-15 beta-lactamases in Enterobacteriaceae causing hospital- and community-acquired urinary tract infections as early as 2004, in Dar es Salaam, Tanzania. BMC Infect. Dis. 17:282.

8. Trecarichi, E.M., R. Cauda, and M. Tumbarello. 2012. Detecting risk and predicting patient mortality in patients with extended-spectrum beta-lactamase-producing Enterobacteriaceae bloodstream infections. Fut. Microbiol. 7: 1173-1189.

9. Reddy, P., M. Malczynski, A. Obias, S. Reiner, N. Jin, J. Huang, G.A. Noskin, and T. Zembower. 2007. Screening 
for extended-spectrum beta-lactamase-producing Enterobacteriaceae among high-risk patients and rates of subsequent bacteremia. Clin. Infect. Dis. 45:846-852.

10. Kiddee, A., K. Assawatheptawee, A. Na-Udom, P. Boonsawang, P. Treebupachatsakul, T.R. Walsh, and P.R. Niumsup. 2019. Risk factors for extended-spectrum $\beta$-lactamase-producing enterobacteriaceae carriage in patients admitted to intensive care unit in a tertiary care hospital in Thailand. Microb. Drug Resist. 25:1182-1190.

11. Sonda, T., H. Kumburu, M. van Zwetselaar, M. Alifrangis, B.T. Mmbaga, O. Lund, F.M. Aarestrup, and G. Kibiki. 2018. Prevalence and risk factors for CTX-M gramnegative bacteria in hospitalized patients at a tertiary care hospital in Kilimanjaro, Tanzania. Eur. J. Clin. Microbiol. Infect. Dis. 37:897-906.

12. Moremi, N., H. Claus, L. Rutta, M. Frosch, U. Vogel, and S.E. Mshana. 2018. High carriage rate of extended-spectrum beta-lactamase-producing Enterobacteriaceae among patients admitted for surgery in Tanzanian hospitals with a low rate of endogenous surgical site infections. J. Hosp. Infect. 100:47-53.

13. Blomberg, B., K.P. Manji, W.K. Urassa, B.S. Tamim, D.S. Mwakagile, R. Jureen, V. Msangi, M.G. Tellevik, M. Holberg-Petersen, S. Harthug, S.Y. Maselle, and N. Langeland. 2007. Antimicrobial resistance predicts death in Tanzanian children with bloodstream infections: a prospective cohort study. BMC Infect. Dis. 7:43.

14. Tellevik, M.G., B. Blomberg, O. Kommedal, S.Y. Maselle, N. Langeland, and S.J. Moyo. 2016. High prevalence of faecal carriage of ESBL-producing Enterobacteriaceae among children in Dar es Salaam, Tanzania. PLoS One. 11: $\mathrm{e} 0168024$

15. Moremi, N., H. Claus, U. Vogel, and S.E. Mshana. 2017. Faecal carriage of CTX-M extended-spectrum beta-lactamaseproducing Enterobacteriaceae among street children dwelling in Mwanza city, Tanzania. PLoS One. 12:e0184592.

16. Mshana, S.E., L. Falgenhauer, M.M. Mirambo, M.F. Mushi, N. Moremi, R. Julius, J. Seni, C. Imirzalioglu, M. Matee, and T. Chakraborty. 2016. Predictors of blaCTX-M15 in varieties of Escherichia coli genotypes from humans in community settings in Mwanza, Tanzania. BMC Infect. Dis. 16:187.

17. Wilmore, S.M.S., K. Kranzer, A. Williams, B. Makamure, A.F. Nhidza, J. Mayini, T. Bandason, J. Metcalfe, M.P. Nicol, I. Balakrishnan, M.J. Ellington, N. Woodford, S. Hopkins, T.D. McHugh, and R.A. Ferrand. 2017. Carriage of extended-spectrum beta-lactamase-producing Enterobacteriaceae in HIV-infected children in Zimbabwe. J. Med. Microbiol. 66:609-615.

18. Tanzania Commission for AIDS (TACAIDS), Zanzibar AIDS Commission (ZAC). Tanzania HIV Impact Survey (THIS) 2016-2017: Final Report. Dar es Salaam, Tanzania. December 2018. https://phia.icap.columbia.edu/wp-content/ uploads/2019/06/FINAL_THIS-2016-2017_Final-Report_06 .21.19_for-web_TS.pdf

19. Jazmati, N., T. Jazmati, and A. Hamprecht. 2017. Importance of pre-enrichment for detection of third-generation cephalosporin-resistant Enterobacteriaceae (3GCREB) from rectal swabs. Eur. J. Clin. Microbiol. Infect. Dis. 36:18471851.
20. Kommedal, O., J.L. Aasen, and P.C. Lindemann. 2016. Genetic antimicrobial susceptibility testing in Gram-negative sepsis-impact on time to results in a routine laboratory. APMIS. 124:603-610.

21. Ouedraogo, A.S., S. Sanou, A. Kissou, A. Poda, S. Aberkane, N. Bouzinbi, B. Nacro, R. Ouedraogo, P. Van De Perre, C. Carriere, D. Decré, H. Jean-Pierre, and S. Godreuil. 2017. Fecal carriage of Enterobacteriaceae producing extended-spectrum beta-lactamases in hospitalized patients and healthy community volunteers in Burkina Faso. Microb. Drug Resist. 23:63-70.

22. Sanneh, B., A. Kebbeh, H.S. Jallow, Y. Camara, L.W. Mwamakamba, I.F. Ceesay, E. Barrow, F.O. Sowe, S.M. Sambou, I. Baldeh, A. Jallow, M.A.J. Raul, and A. Andremont. 2018. Prevalence and risk factors for faecal carriage of Extended Spectrum beta-lactamase producing Enterobacteriaceae among food handlers in lower basic schools in West Coast Region of The Gambia. PLoS One. 13:e0200894.

23. Barguigua, A., H. Ouair, F. El Otmani, R. Saile, N. El Mdaghri, M. El Azhari, and M. Timinouni. 2015. Fecal carriage of extended-spectrum beta-lactamase-producing Enterobacteriaceae in community setting in Casablanca. Infect. Dis. (Lond.). 47:27-32.

24. Kluytmans-van den Bergh, M.F., C. Verhulst, L.E. Willemsen, E. Verkade, M.J. Bonten, and J.A. Kluytmans. 2015. Rectal carriage of extended-spectrum-beta-lactamase-producing Enterobacteriaceae in hospitalized patients: selective preenrichment increases yield of screening. J. Clin. Microbiol. 53:2709-2712.

25. Murk, J.-L.A.N., E.R. Heddema, D.L.J. Hess, J.A. Bogaards, C.M.J.E. Vandenbroucke-Grauls, and Y.J. DebetsOssenkopp. 2009. Enrichment broth improved detection of extended-spectrum-beta-lactamase-producing bacteria in throat and rectal surveillance cultures of samples from patients in intensive care units. J. Clin. Microbiol. 47:18851887.

26. Urban, C., N. Mariano, P.A. Bradford, M. Tuckman, S. Segal-Maurer, W. Wehbeh, L. Grenner, R. Colon-Urban, B. Johnston, J.R. Johnson, and J.J. Rahal. 2010. Identification of CTX-M beta-lactamases in Escherichia coli from hospitalized patients and residents of long-term care facilities. Diagn. Microbiol. Infect. Dis. 66:402-406.

27. Diaz, M.A., J.R. Hernandez-Bello, J. Rodriguez-Bano, L. Martinez-Martinez, J. Calvo, J. Blanco, A. Pascual, and Spanish Group for Nosocomial Infections (GEIH). 2010. Diversity of Escherichia coli strains producing extendedspectrum beta-lactamases in Spain: second nationwide study. J. Clin. Microbiol. 48:2840-2845.

Address correspondence to: Joel Manyahi, MD Department of Microbiology and Immunology Muhimbili University of Health and Allied Sciences P.O. Box 65001

Dar es Salaam Tanzania

E-mail: joel.manyahi@uib.no,manyahijoel@yahoo.com 